\title{
Partially Replacing the Emulsified Asphalt in Cement Emulsified Asphalt Mortars with Epoxy Emulsion: Mechanical Properties and Durability Study
}

\author{
Ning Xu $\mathbb{D}^{\mathrm{D}},{ }^{1}$ Kexin Huang, ${ }^{2}$ Weiguang Li $\left(\mathbb{D},{ }^{1} \mathrm{Xin} \mathrm{Han}^{3}\right.$ Lijuan Han, ${ }^{3}$ and Chanchan $\mathrm{Li}^{1}$ \\ ${ }^{1}$ School of Highway, Chang'an University, Xi'an 710064, China \\ ${ }^{2} X i$ 'an University of Architecture and Technology and College, Xi'an 710064, China \\ ${ }^{3}$ Zhengping Road and Bridge Construction Co.,Ltd., Xining 810000, China
}

Correspondence should be addressed to Ning Xu; xn@chd.edu.cn and Weiguang Li; chdlwg@126.com

Received 11 June 2021; Revised 22 July 2021; Accepted 2 November 2021; Published 19 November 2021

Academic Editor: Alicia E. Ares

Copyright $(2021$ Ning Xu et al. This is an open access article distributed under the Creative Commons Attribution License, which permits unrestricted use, distribution, and reproduction in any medium, provided the original work is properly cited.

Cement emulsified asphalt (CEA) mortars achieve insufficient bond strength with substrate cement concrete slab. To ameliorate problems emerging from this, the emulsified asphalt (EA) in CEA mortars was partly replaced by epoxy emulsion (EE) at contents of $0 \%, 10 \%, 20 \%$, and $30 \%$, yielding CEA mortars with enhanced properties. The bond strength, mechanical strength, toughness, and durability (including drying shrinkage and erosion resistance) of modified CEA mortars were assessed. The results showed that partial replacement of EA with EE improved the bond strength, mechanical strength, drying shrinkage, and erosion resistance of CEA mortars. A good correlation was found between the proportions of the EE replacement and the bond strength of CEA mortars. Partial replacement of EA with a small amount of EE exerted no significant effect on the toughness of CEA mortar. The stronger network structure of CEA mortars containing EE improved the compactness, thus improving the performance of CEA mortars. Based on these findings, EE is suggested as partial replacement of EA for enhancing the properties of CEA mortars.

\section{Introduction}

Today, polymer-modified cement mortars are widely used in concrete structures as finishing or repair materials to prolong the service life of infrastructures $[1,2]$. It has been acknowledged that polymer-modified cement mortars not only maintain the properties of cement mortars but also utilize the properties of polymers. Thus, they obtain good bond strength, excellent toughness, and other desired properties [3]. Cement emulsified asphalt (CEA) mortars retain most of the characteristics of cement and asphalt, including long fatigue life, the low-temperature sensitivity of cement, and the high toughness of asphalt. Because of the above properties, CEA mortars are commonly applied in railway tracks as a bedding layer between the track slab and the concrete foundation to dissipate and reduce track vibrations generated by trains passing at high speeds. Additionally, CEA mortars are also used as repair materials for cement pavements or other cement infrastructures $[4,5]$.

CEA mortars need to have good coordination deformation ability and interface bond strength with the concrete slab when used as a bedding layer between the track slab and the concrete foundation or as repair materials. However, researches by Liu et al. [6] and Peng et al. [7] indicated that CEA mortars do not yield sufficient interfacial bond strength with cement concrete. Measures to improve the bond strength of CEA mortars have received considerable attention. Liu et al. [8] pointed out that incorporation of stabilizers in CEA mortars increased the interfacial bonding strength. The debonding rate and gap width of CEA mortars with stabilizers decreased sharply. Peng et al. [7] investigated the interfacial bonding strength of two types of CEA mortars via pull-off tests and showed that the bonding strength of the CEA mortar with a high $\mathrm{A} / \mathrm{C}$ ratio exceeded that with low $\mathrm{A} / \mathrm{C}$ ratio. The bonding strength of CEA mortars was also enhanced by polymer latexes. Zhang et al. [9] showed that 
the addition of acrylate latexes and expansion agent improved the interlayer bonding of CEA mortar and concrete composite specimens. The reason for this improvement was the excellent bond performance of acrylate latexes and the enhanced mechanical interlock achieved by the expansion agent.

It has been suggested that polymer latexes may be used as a modifier for cement mortar and concrete to improve the adhesion and bond strength because of its excellent bonding properties and microstructure transformation of mortar and concrete [10-12]. Epoxy emulsion (EE), as common polymer latexes, has been widely applied to modify cement mortars or concrete. Xiao et al. [13] prepared a high-performance cement with $\mathrm{EE}$ and showed that the addition of EE slightly increased the mechanical properties and corruptness resistance of modified cement mortars. The reason is the formation of a three-dimensional structure in the cement hydration system, which bridges phases by EE. The dense structure of cement epoxy emulsion mortar (because of the cross-linking structure formed by cured epoxy resin with cement hydration products) also enhances erosion resistance [14]. Furthermore, Zheng et al. [15] investigated the hydration process of EE enhanced cement mortar and showed that the evolution of the modified cementbased paste can be divided into four stages based on the normalized heat flow. The bonding strength and bending ability of mortars were improved by the addition of epoxy resin. Studies by Pang et al. [16] and Zuo et al. [17] also showed that the mechanical strength and bond strength of cement epoxy emulsion mortar improved with increasing EE contents. Numerous attempts have been made to obtain EE-modified EA composite emulsions. $\mathrm{Gu}$ et al. [18] investigated the compatibility between the cured phase-inversion waterborne epoxy resin and EA, showing that increasing the content of waterborne epoxy resin improved the compatibility of the composite emulsion. Liu et al. [19] showed that the components and network microstructure of EE modified EA enhanced the cohesion property and viscoelasticity of this material. Li et al. [20] found that waterborne epoxy resin significantly increased the complex modulus of asphalt emulsion residues. Based on the above findings, it is clear that EE can be added to cement or EA, thus, enhancing their properties. CEA mortars mainly consist of cement and EA. However, attempts to utilize the advantages of EE to obtain reinforced CEA mortars with better bond strength, mechanical strength, and other properties remain inadequate to date. The bond strength and other properties of CEA mortars with partial replacement of EA by EE remain unclear.

In this study, part of EA in CEA mortars was replaced by EE with additions varying from $0 \%$ to $30 \%$ (at increments of $10 \%)$. The mechanical properties including bond strength, mechanical strength, toughness, anddurability including drying shrinkage and erosion resistance of modified CEA mortars wereinvestigated.

\section{Materials and Methods}

\subsection{Raw Materials}

(1) Cement not only provides the mechanical strength needed for CEA mortars but also absorbs water in EA and EE during the hydration process [21-23].
Table 1 presents the properties of grade 42.5 ordinary Portland cement (OPC) produced by Qinling Factory (Shaanxi, Xi'an, China). The test methods of cement followed Chinese Standard GB 175-2007.

(2) SBR cationic EA was used in the experiment, as shown in Figure 1(a). Its properties are shown in Table 2. The test methods of EA followed Chinese Standard JTG E20- 2011.

(3) The main properties of nonionic waterborne EE and curing agent purchased from the Junhua building materials factory (Shanxi, Taiyuan, China) are shown in Tables 3 and 4, respectively. The appearances of EE and the curing agent are shown in Figures 1(b) and 1(c), respectively. The test methods of waterborne EE and the curing agent followed Chinese Standard GB/ T 36797-2018. The type of epoxy resin with an epoxy value of $0.51 \mathrm{~mol} / 100 \mathrm{~g}$ in the epoxy emulsion was $E$ 51. The curing agent was an amine curing agent with an amine value of $320 \mathrm{~mol} / 100 \mathrm{~g}$. The ratio of EE to the curing agent was $1: 1$ when used for CEA mortars, which was chosen according to the experience informed by a laboratory test.

(4) River sand with a particle size between 0.32 and $4.75 \mathrm{~mm}$ and a fineness modulus of 2.7 was used as fine aggregate. Tap water was used in the experiment.

(5) Studies by Tan et al. [24] and Ouyang et al. [25] showed that the addition of additives can effectively improve the performance of cement mortar. To improve the fluidity of CEA mortar, a naphthalene water-reducing agent (FDN-2) with a water-reducing rate of $20 \%$ was used at proportions of $1.8 \%$ by mass of cement according to practical experience. The FDN-2 water-reducing agent compounded by the $\beta$-naphthalene sulfonate was obtained from Shandong Wanshan Chemical Co., Ltd. (Shandong, Jinan, China). As air was introduced into the cement mortar mixture during the mixing process, a defoamer was necessary to reduce small bubbles. Thus, tributyl phosphate $\left(\mathrm{C}_{12} \mathrm{H}_{27} \mathrm{O}_{4} \mathrm{P}\right)$ obtained from Shandong Xinheng Chemical Co., Ltd. (Shandong, Jinan, China) was used as a defoamer at a ratio of $0.1 \%$ by mass of cement according to practical experience. In the research of Buoso et al. [26], Vo and Plank [27], and Liu et al. [28], the tributyl phosphate was also applied as a defoamer for cement mortar.

2.2. Preparation of Cement Emulsified Asphalt Mortar Samples. Because of their better fluidity and mechanical strength (as identified by previous laboratory tests), CEA mortars with $40 \%$ EA content (by mass of cement) were selected. To determine the proportions of EE to replace EA, the compatibility and distribution of EE and EA in composite emulsions after curing were characterized. Figure 2 shows the fluorescence microscopic (FM) images of composite emulsions where EA was replaced by different contents of EE. In the FM images, epoxy resin is shown in yellow, while asphalt appears black. The area of the yellow 
TABLE 1: Main properties of ordinary Portland cement (PO 42.5).

\begin{tabular}{|c|c|c|c|c|c|}
\hline \multicolumn{2}{|c|}{ Setting time $(\mathrm{min})$} & \multicolumn{2}{|c|}{ Flexural strength $(\mathrm{MPa})$} & \multicolumn{2}{|c|}{$\begin{array}{c}\text { Compressive strength } \\
(\mathrm{MPa})\end{array}$} \\
\hline Initial setting & Final setting & $3 \mathrm{~d}$ & $28 \mathrm{~d}$ & $3 \mathrm{~d}$ & $28 \mathrm{~d}$ \\
\hline 250 & 303 & 3.5 & 6.8 & 18.4 & 47.8 \\
\hline
\end{tabular}

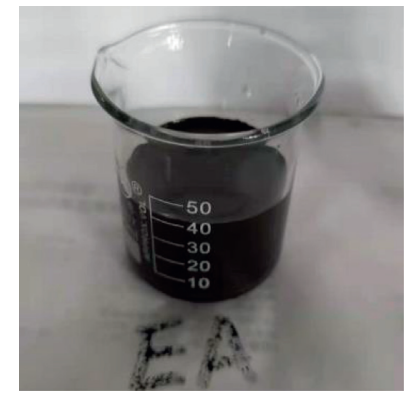

(a)

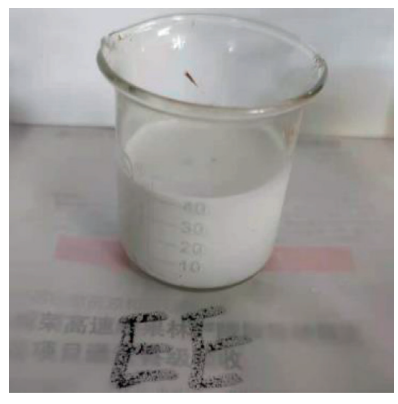

(b)

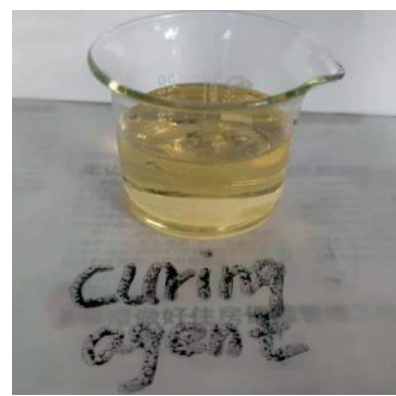

(c)

FIGURE 1: Emulsions used in the test: (a) emulsified asphalt, (b) epoxy emulsion, and (c) curing agent.

TABLE 2: Main properties of emulsified asphalt.

\begin{tabular}{lcccc}
\hline The average particle diameter $(\mu \mathrm{m})$ & Storage stability $\left(1 \mathrm{~d}, 20^{\circ} \mathrm{C}\right)(\%)$ & Evaporation residue $(\%)$ & $25^{\circ} \mathrm{C}$ penetration $(0.1 \mathrm{~mm})$ & $\begin{array}{l}\text { Particle } \\
\text { polarity }\end{array}$ \\
\hline 2.5 & 0.7 & 58.5 & 94 & Cationic \\
\hline
\end{tabular}

TABLE 3: Main properties of the waterborne epoxy emulsion.

\begin{tabular}{lccccc}
\hline Appearance & $\begin{array}{l}\text { Particle } \\
\text { polarity }\end{array}$ & Solid content $(\%)$ & $25^{\circ} \mathrm{C}$ viscosity $(\mathrm{mPa} \cdot \mathrm{s})$ & Centrifugal stability & $\begin{array}{c}\text { Storage } \\
\text { stability }\end{array}$ \\
\hline Milky white & Nonionic & 60 & 225 & $\begin{array}{c}\text { Centrifugation without delamination } \\
(30 \mathrm{~min}, 3000 \mathrm{n} / \mathrm{min})\end{array}$ & No stratification in 24h \\
\hline
\end{tabular}

TABLE 4: Main properties of the curing agent.

\begin{tabular}{|c|c|c|c|c|c|}
\hline Appearance & Solid content (\%) & Amine value $(\mathrm{mol} / 100 \mathrm{~g})$ & Volatile organic compounds contents $(\mathrm{g} / \mathrm{L})$ & Particle polarity & Curing rate \\
\hline Brown liquid & 50 & 320 & 32 & Nonionic & Medium \\
\hline
\end{tabular}

epoxy resin in the FM images increased with increasing EE proportions. At an EE dosage below 30\%, the epoxy resin was evenly distributed in the asphalt and formed a structure with asphalt as a continuous phase and epoxy resin as a dispersed phase. At an EE dosage of 30\%, the epoxy resin interacted with asphalt and formed a network structure. However, at an EE dosage of more than 30\%, EA and EE composite emulsion after curing showed an agglomeration structure, which was not conducive to the formation of an asphalt-epoxy network structure. This indicates that EA and EE could mix well when the proportion of EE replacing EA is less than $30 \%$.

Thus, in this study, the replacement ratio of EE replacingEA was determined as $0 \%, 10 \%, 20 \%$, and $30 \%$, respectively. Then, four types of CEA mortars (i.e., I, II, III, and IV) were designed. The proportions of CEA mortars and their fluidity tested according to Chinese Standard GB/ T2419-2005 are presented in Table 5. All samples were designed with a water-cement ratio of 0.38 and a cement-sand ratio of $1: 2$. It should be noted that the water contained in EA, EE, and the curing agent is not included in Table 5 . The required water was calculated by equation (1):

$$
\begin{aligned}
M_{\text {water }}= & 0.38 * M_{\text {cement }}-0.415 * M_{E A}-0.4 * M_{E E} \\
& -0.5 * M_{\text {curingagent }},
\end{aligned}
$$

where $M_{\text {water }}$ refers to the mass of water in Table $5(\mathrm{~g})$; $M_{\text {cement }}$ refers to the mass of cement $(\mathrm{g}) ; M_{\mathrm{EA}}$ refers to the 


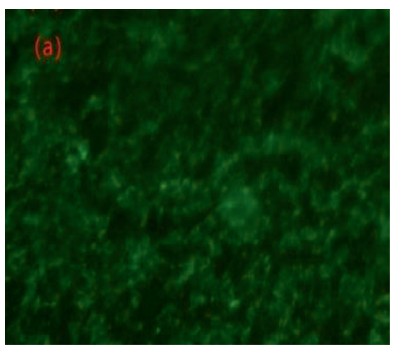

(a)

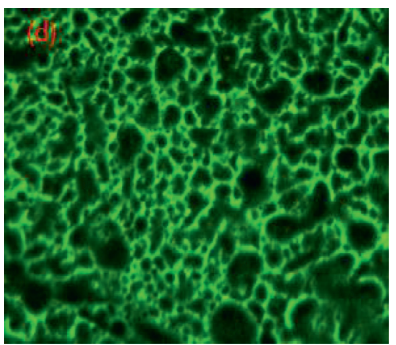

(d)

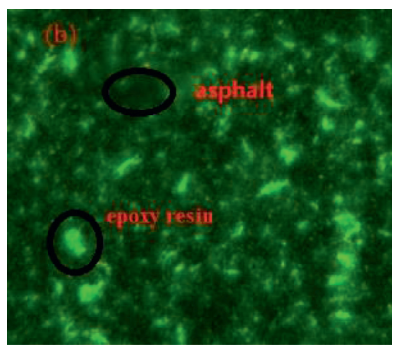

(b)

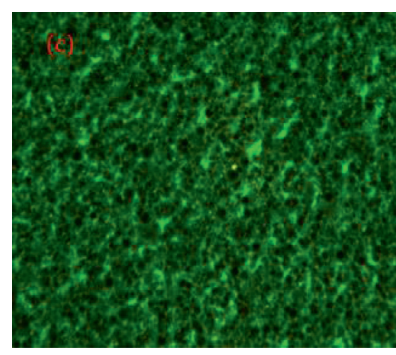

(c)

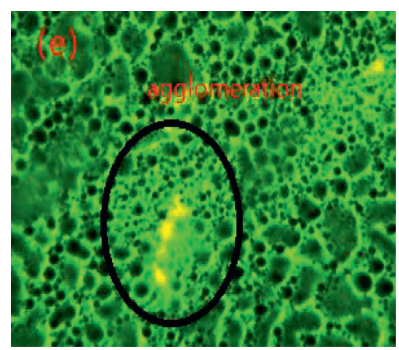

(e)

Figure 2: Fluorescence microscopic images of emulsified asphalt replaced by different contents of epoxy emulsion: (a) $0 \%$, (b) $10 \%$, (c) $20 \%$, (d) $30 \%$, and (e) $40 \%$.

TABle 5: Proportions and fluidity of cement emulsified asphalt mortars.

\begin{tabular}{lccccccccc}
\hline Test number & EE $(\mathrm{g})$ & $\begin{array}{c}\text { Curing } \\
\text { agent }(\mathrm{g})\end{array}$ & EA $(\mathrm{g})$ & Cement $(\mathrm{g})$ & Water $(\mathrm{g})$ & Sand $(\mathrm{g})$ & $\begin{array}{c}\text { Water-reducing } \\
\text { agent }(\mathrm{g})\end{array}$ & Defoamer agent (g) & Fluidity $(\mathrm{mm})$ \\
\hline I & 0 & 0 & 160 & 400 & 85.60 & 800 & 7.2 & 0.4 & 232 \\
II & 16 & 16 & 144 & 400 & 77.84 & 800 & 7.2 & 0.4 & 220 \\
III & 32 & 32 & 128 & 400 & 70.08 & 800 & 7.2 & 0.4 & 220 \\
IV & 48 & 48 & 112 & 400 & 63.32 & 800 & 7.2 & 0.4 & 217 \\
\hline
\end{tabular}

mass of EA ( $\mathrm{g}) ; M_{\mathrm{EE}}$ refers to the mass of $\mathrm{EE}(\mathrm{g}) ; M_{\text {curingagent }}$ refers to the mass of curing agent $(\mathrm{g})$.

During mixing, cement, sand, and additives were poured into the stirring pot and were evenly stirred for $30 \mathrm{~s}$. Then, water, EA, EE, and curing agent were prestirred until uniformity and blended with the mix for 3-4 min. Finally, mortars were shaped by the corresponding mold.

2.3. Bond Strength Test. As applied by Qiao et al. [29], the flexural bond strength test was used to characterize the bond strength between the repair mortar and the OPC mortar/concrete. This method was also used to evaluate the bond performance of CEA mortars containing EE according to the Chinese standard JC/T 2381-2016. A $40 \mathrm{~mm} \times 40 \mathrm{~mm} \times 160 \mathrm{~mm}$ beam consisted of half of CEA mortars and the other half of OPC mortars. The part with OPC mortar was first formed and cured under standard conditions for $28 \mathrm{~d}$. Then, CEA mortar was poured beside OPC mortars, and the samples were placed under standard conditions for a further 3, 7, and $28 \mathrm{~d}$. Figure 3 presents the specimen preparation and testing process of the bond strength test. The results were obtained by dividing the maximum force by the bond area. Two specimens were formed in each group, and the average value was taken.
2.4. Mechanical Strength Test. The flexural strength and compressive strength of CEA mortars at $3 \mathrm{~d}, 7 \mathrm{~d}$, and $28 \mathrm{~d}$ were tested to characterize the mechanical strength of CEA mortars according to Chinese Standard DL/T5126-2001. Prism specimens with a size of $40 \mathrm{~mm} \times 40 \mathrm{~mm} \times 160 \mathrm{~mm}$ were used for the flexural strength tests. The blocks that had broken after the flexural strength test were used for the compressive strength test. Three specimens were formed in each group, and the average value was taken.

2.5. Toughness Test. The toughness of CEA mortars was characterized by fracture toughness and impact toughness. The ratio of compressive strength to flexural strength (RCF), a convenient and direct reflection of the fracture toughness of the materials, was determined based on the obtained compressive and flexural strengths [30].

The impact toughness used to reflect the toughness of the cement mortar was evaluated by a self-made dropweight test. This self-made drop-weight test was designed in reference to the drop-weight test recommended by the American Concrete Institute Committee 554 (ACI Committee 544) [31]. A $300 \mathrm{~mm} \times 300 \mathrm{~mm} \times 50 \mathrm{~mm}$ mold was used to form OPC mortar, which was placed under standard conditions with a relative humidity of $95 \%$ and a temperature of $20 \pm 2^{\circ} \mathrm{C}$ for $28 \mathrm{~d}$. Then, CEA mortars with 


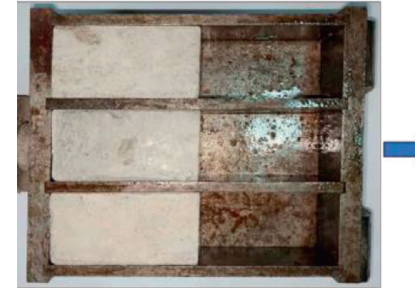

Half part of OPC mortar was first formed

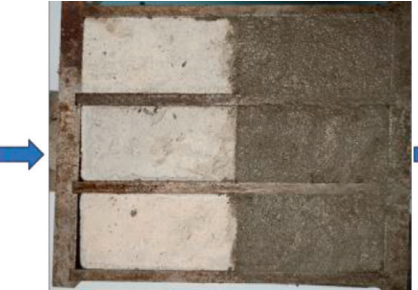

CEA mortar was poured beside the part of OPC mortar

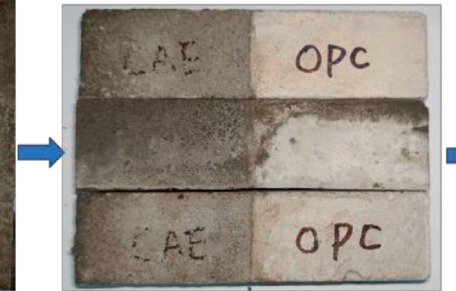

Demold

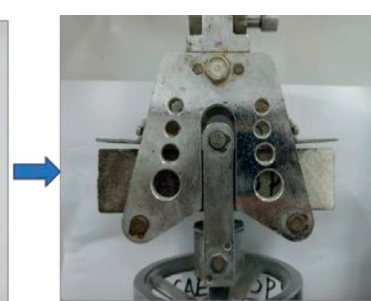

Testing

FIGURE 3: Specimen preparation and testing process of bond strength test.

a thickness of $20 \mathrm{~mm}$ were placed on the upper of the OPC concretes and the samples were cured under standard conditions for a further $28 \mathrm{~d}$. Figure 4 presents the specimen preparation and testing process of self-made drop-weight test. A steel ball with a mass of $1.835 \mathrm{~kg}$ and a diameter of $63.5 \mathrm{~mm}$ fell freely from $200 \mathrm{~mm}$ to the surface of the specimen. The impact energy absorbed by the specimen, used to reflect the impact resistance, was calculated by equations (2) and (3) according to ACI Committee 544. Three specimens were formed in each group, and the average value was taken.

$$
\begin{gathered}
W=n_{2} \cdot m \cdot g \cdot h, \\
\Delta W=\Delta n \cdot m \cdot g \cdot h,
\end{gathered}
$$

where $W$ refers to whole impact energy absorbed by the specimen during the failure process $(\mathrm{N} \cdot \mathrm{m}) ; \Delta W$ refers to the impact energy absorbed by the specimen after initial cracking (N.m); $\Delta n=n_{2}-n_{1} ; n_{1}$ refers to the number of impacts until initial cracking occurred; $n_{2}$ refers to the number of impacts until specimen failure occurred. Moreover, $g$ refers to the acceleration of gravity $(9.8 \mathrm{~N} / \mathrm{kg})$; $m$ refers to the mass of the steel ball $(1.835 \mathrm{~kg}) ; h$ refers to the drop height of the steel ball $(200 \mathrm{~mm})$.

2.6. Drying Shrinkage Test. The drying shrinkage of CEA mortars was tested at 3, 7, 14,21, 28, and $56 \mathrm{~d}$ according to Chinese Standard JC-T603-2004. Prism specimens with a size of $25 \mathrm{~mm} \times 25 \mathrm{~mm} \times 280 \mathrm{~mm}$ were used for drying shrinkage tests. Because of the small variation of drying shrinkage of cement mortar, one specimen was tested in each group. The drying shrinkage value of CEA mortars was calculated by equation (4):

$$
S_{i}=\frac{\left(L_{0}-L_{i}\right)}{250}
$$

where $S_{i}$ refers to the drying shrinkage value of the specimen for $i$ days (\%); $L_{0}$ refers to the initial measurement length of the specimen (mm); $L_{i}$ refers to the measurement length of the specimen after $i$ days $(\mathrm{mm})$; and 250 refers to the effective length of the specimen $(\mathrm{mm})$.

2.7. Erosion Resistance Test. Prism specimens with a size of $40 \mathrm{~mm} \times 40 \mathrm{~mm} \times 160 \mathrm{~mm}$ were immersed in erosion solutions (acid solution with 1\% hydrochloric acid content or sulfate solution with $5 \%$ sulfate content) for $60 \mathrm{~d}$ [32]. The mass loss and mechanical strength loss of specimens were calculated by equations (5) and (6), respectively. Three specimens were formed in each group, and the average value was taken:

$$
\begin{aligned}
& \Delta m=\frac{\left(m_{0}-m_{60}\right)}{m_{0}} \times 100 \%, \\
& \Delta R=\frac{\left(R_{W}-R_{60}\right)}{R_{W}} \times 100 \%,
\end{aligned}
$$

where $\Delta m$ refers to the mass loss (\%); $m_{0}$ refers to the dry mass of specimens without immersion (g); $m_{60}$ refers to the dry mass of specimens immersed in acid solution or sulfate solution for $60 \mathrm{~d}(\mathrm{~g}) ; \Delta R$ refers to the mechanical strength loss (\%); $R_{w}$ refers to the mechanical strength of specimens immersed in water for $60 \mathrm{~d}(\mathrm{MPa}) ; R_{60}$ refers to the mechanical strength of specimens immersed in acid solution or sulfate solution for $60 \mathrm{~d}(\mathrm{MPa})$.

2.8. Microstructure Analysis. Scanning electron microscopy (SEM, S4800) was adopted to observe the microstructure and morphology of several mortars. Samples were broken into small particles and put into anhydrous ethanol to terminate the hydration reaction. A layer of Au powder was plated on the surface of small particle samples. After vacuum treatment, the morphology was observed by SEM.

\section{Results and Discussion}

3.1. Bond Strength. Figure 5 presents the flexural bond strength of four types of CEA mortars after 3,7 , and $28 \mathrm{~d}$ of curing. The polymer emulsions in CEA mortars tended to penetrate the micropores on the surface of OPC mortar, where they formed a tack coat between CEA mortar and OPC mortar [7]. Larger amounts of polymer emulsions with good flowability permeated into the interface between CEA mortar and OPC mortar at the early ages of CEA mortars. However, the amounts of emulsions permeating into the interface decreased with the gradual hardening of CEA mortars. Figure 5 shows that the flexural bond strength of CEA mortars increased greatly from $3 \mathrm{~d}$ to $7 \mathrm{~d}$ and increased slowly from $7 \mathrm{~d}$ to $28 \mathrm{~d}$.

The flexural bond strength of CEA mortar-I merely reached 1.3, 2.7, and $3.2 \mathrm{MPa}$ at ages of 3,7 , and $28 \mathrm{~d}$, 


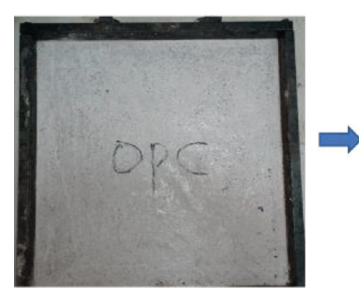

Mortar slab

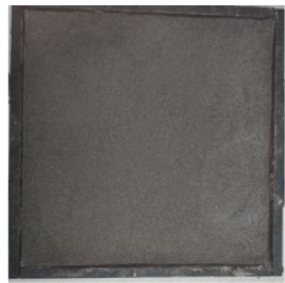

CEA mortar was placed on the upper of the OPC slab

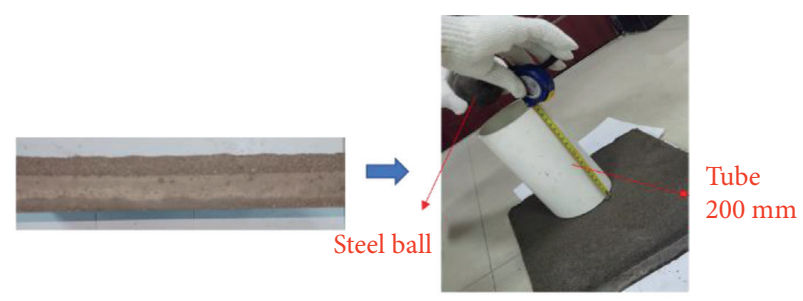

Side view of specimen

Testing

FIGURE 4: Specimen preparation and testing process of self-made drop-weight test.
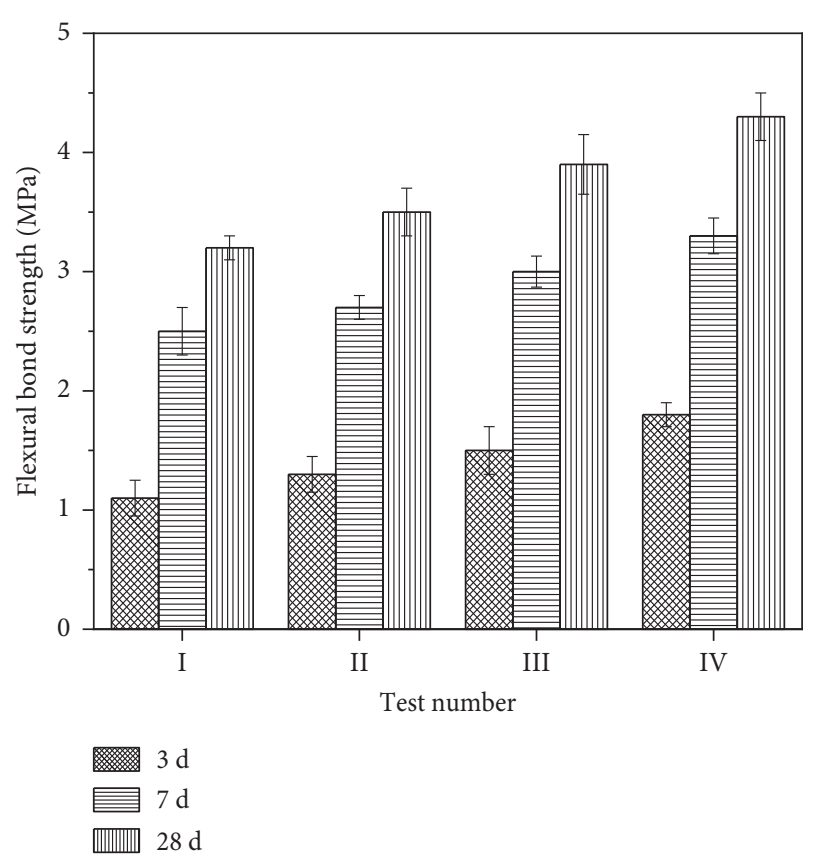

FIgURE 5: Flexural bond strength of cement emulsified asphalt mortars.

respectively. In comparison with CEA mortar-I, the flexural strength of CEA mortar-IV increased by $38.4 \%, 22.2 \%$, and $22.9 \%$ at ages of 3,7 , and $28 \mathrm{~d}$, respectively, yielding $1.8,3.3$, and 4.3 MPa. Clearly, the flexural bond strength of CEA mortars increased with increasing proportions of $\mathrm{EE}$ replacing EA. This can be mainly attributed to the good bonding property of EE. Moreover, the active groups in EE could react with $\mathrm{Al}^{3+}$ or $\mathrm{Ca}^{2+}$ in cement hydration products and form chemical bridge bonds, which stretched across the interface between CEA mortar and OPC mortar [16, 33]. Thus, partial replacement of EA by EE improves the bond strength of CEA mortars.

To establish the relationship between the proportions of EE replacing EA and the flexural bond strength of CEA mortars, a linear regression was conducted by Origin-Pro 2016 (Figure 6). A good correlation was found between the proportions of EE replacing EA and the flexural bond strength of CEA mortars. The correlation coefficient $R^{2}$ between replacement proportions and flexural bond strength at ages of 3,7 , and $28 \mathrm{~d}$ were $0.983,0.988$, and 0.993 , respectively. This also indicated that the proportions of EE replacing EA could reflect the bond strength of CEA mortars containing EE.

3.2. Mechanical Strength. The mechanical strength of cement mortars, including flexural strength and compressive strength, reflects the ability of materials to resist stress and strain. Figure 7 presents the flexural strength and compressive strength of four types of CEA mortars after 3, 7, and $28 \mathrm{~d}$ of curing.

In Figure 7(a), the flexural strength of CEA mortar-I was the lowest among the four types of CEA mortars, merely reaching $3.4,4.0$, and $5.4 \mathrm{MPa}$ at ages of 3,7 , and $28 \mathrm{~d}$, respectively. This is mainly because EA (with low modulus) lowered the mechanical strength of CEA mortars [34, 35]. With increasing proportions of EE replacing EA, the flexural strength of CEA mortars also increased. In comparison with CEA mortar-I, the flexural strength of CEA mortar-IV increased to $4.1,4.9$, and $6.6 \mathrm{MPa}$ at ages of 3,7 , and $28 \mathrm{~d}$, respectively. The variations of compressive strength of CEA mortars with the proportions of EE replacing EA were similar to those observed for flexural strength (Figure $7(\mathrm{~b})$ ). The compressive strength of CEA mortar-IV increased to the maximum among all four types of CEA mortars at ages of 3 , 7 , and $28 \mathrm{~d}$. The content of EA lowering mechanical strength decreased with increasing proportions of EE replacing EA. Moreover, a stronger and denser network structure was formed in CEA mortars because EE (with good bond performance) integrated asphalt and hydration products [16]. Thus, as a partial replacement of EA, EE improved the mechanical strength of CEA mortars.

3.3. Toughness. The RCF, which conveniently and directly reflects the fracture toughness of materials, was determined based on the obtained compressive strengths and flexural strengths in Section 3.2. Figure 8 presents the RCF of four types of CEA mortars after $28 \mathrm{~d}$ of curing. Lower RCF values indicate better fracture toughness. The RCF of CEA mortars decreased slightly with increasing proportions of $\mathrm{EE}$ replacing EA. The RCF of CEA mortar-I reached 6.56. Compared with CEA mortar-I, the RCF of CEA mortars-II, III, and IV decreased to 6.48, 6.40, and 6.21, respectively. However, the decreases in RCF were small. The RCF of CEA mortar-IV only decreased by $5.3 \%$ compared with that of CEA mortar-I. This indicates that the partial replacement of 


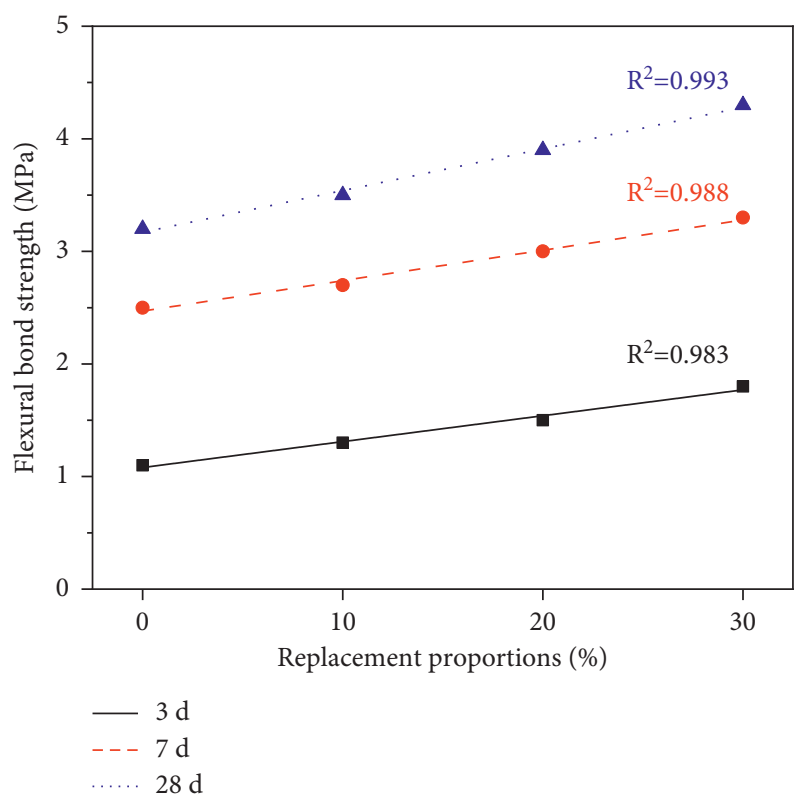

FIGURE 6: Relationships between the proportions of epoxy emulsion replacing emulsified asphalt and the bond strength of cement emulsified asphalt mortars.

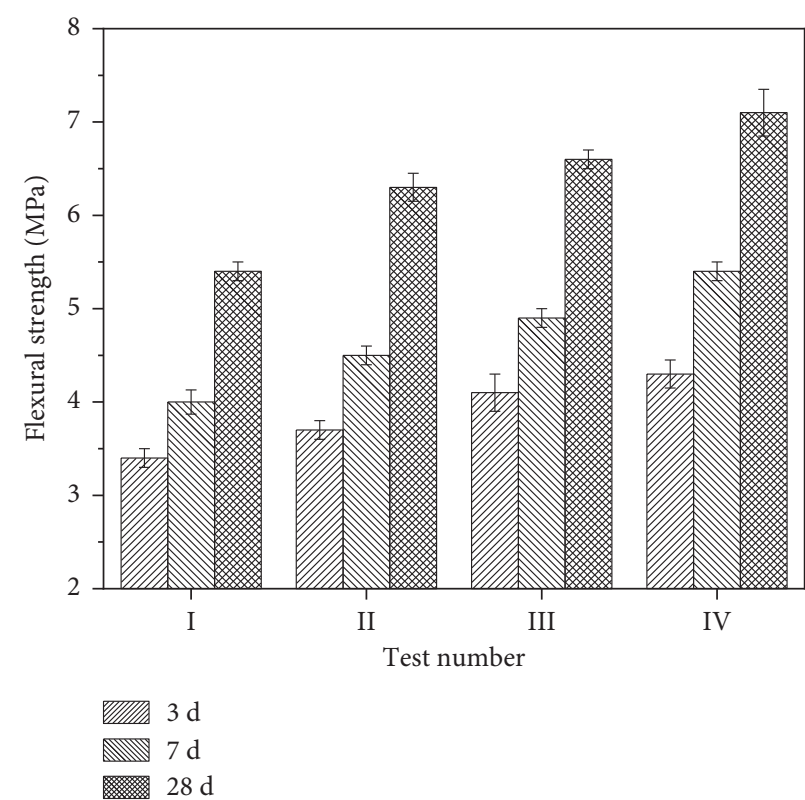

(a)

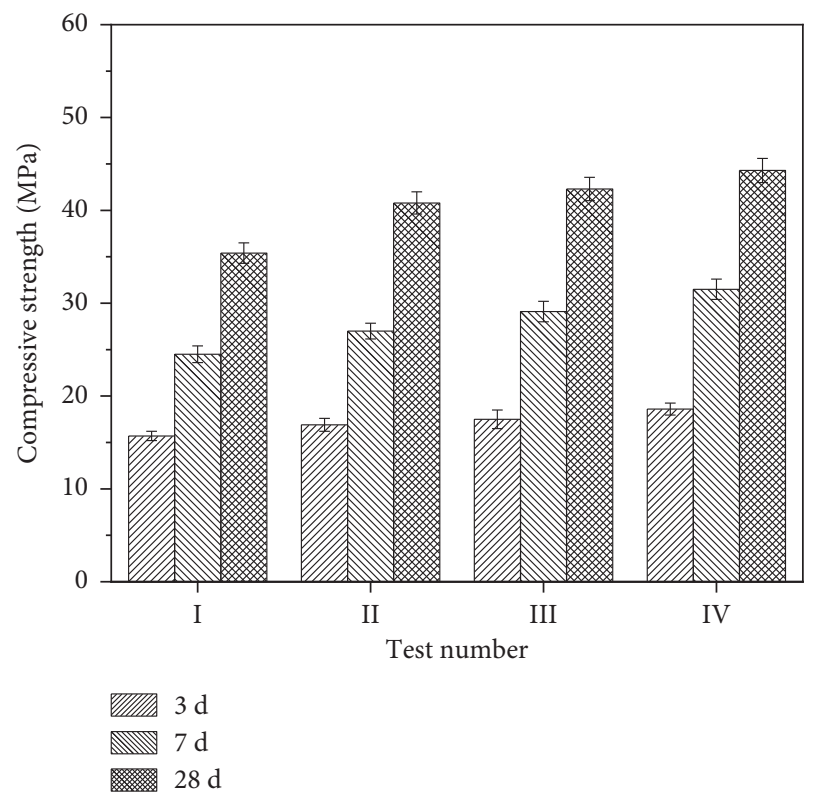

(b)

FIgURE 7: Mechanical strength of cement emulsified asphalt mortars: (a) flexural strength and (b) compressive strength.

EA by EE exerts no obvious effect on the fracture toughness of CEA mortars.

To further study the toughness of CEA mortars containing EE, a self-made drop-weight test apparatus was employed to reflect the impact toughness of CEA mortars after $28 \mathrm{~d}$ of curing. Figure 9 presents the results of the selfmade drop-weight test. The higher value of impact energy absorbed by the specimens $(W)$ indicates better impact toughness. The $W$ of CEA mortars increased slightly with increasing proportions of EE replacing EA. However, the increases of $\mathrm{W}$ were small. The RCF of CEA mortar-IV was highest among all four types of CEA mortars, which only increased by $8.5 \%$ compared with that of CEA mortar-I. This indicates that the partial replacement of EA by EE has no obvious effect on the impact toughness of CEA mortars. The evenly dispersed EA membranes were interwoven with cement hydration products and distributed throughout microcracks contained in cement mortars [36, 37]. This provided sufficient toughness for CEA mortars to resist crack propagation. Though epoxy resin could form a cross- 


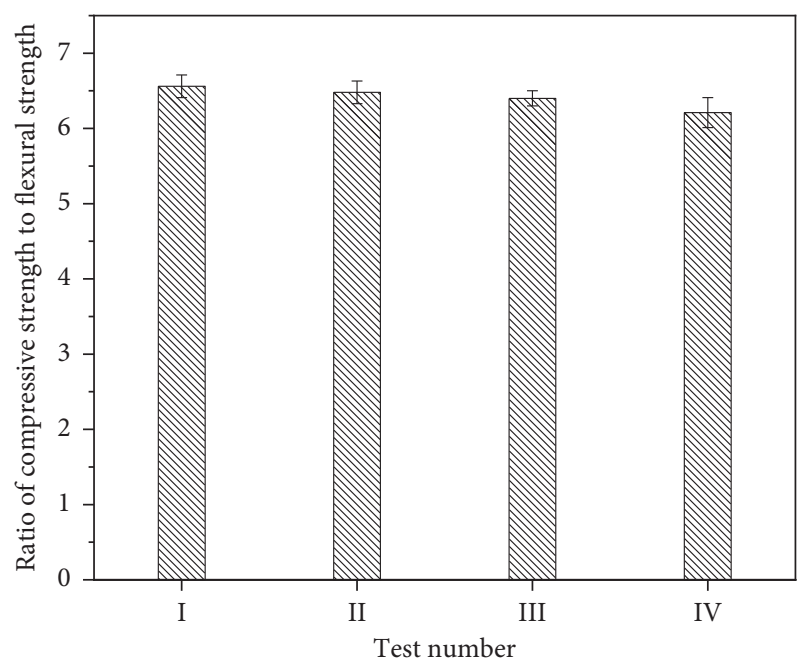

Figure 8: Ratio of compressive strength to flexural strength of four types of cement emulsified asphalt mortars.

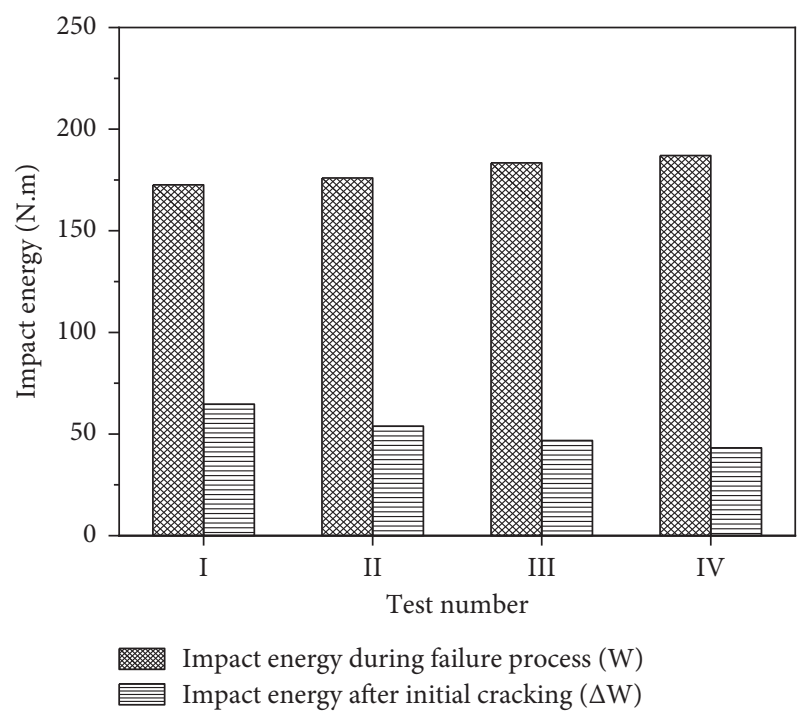

FIGURE 9: Self-made drop-weight test results of cement emulsified asphalt mortars.

linking structure with cement hydration products, the brittleness of $\mathrm{EE}$ after curing offset the weak cross-linking structure formed by a small amount of EE [17]. Thus, partial replacement of EA by EE achieves no obvious improvement effect on the toughness of CEA mortars.

Interestingly, the impact energy absorbed by specimens after initial cracking $(\Delta W)$ decreased with increasing proportions of EE replacing EA. Cured epoxy resin, with its large brittleness, weakened the ability of CEA mortars to continue absorbing energy once cement mortars cracked [16]. This suggests that a large amount of EE may have adverse effects on the toughness of CEA mortars.

3.4. Drying Shrinkage. Figure 10 presents the drying shrinkage of CEA mortars at 3, 7, 14, 21, 28, and $56 \mathrm{~d}$. With increasing curing age, the drying shrinkage for four types of
CEA mortars increased. The changing trends of drying shrinkage for four types of CEA mortars were similar. Moreover, the variation rules of drying shrinkage with curing ages for CEA mortars were consistent with the results of Rutherford et al. [38]. The drying shrinkage of CEA mortars increased greatly within $28 \mathrm{~d}$ (particularly within the first $7 \mathrm{~d}$ ) and increased slowly from $28 \mathrm{~d}$ to $56 \mathrm{~d}$. This was mainly because of the rapid hydration process, which consumed considerable water in CEA mortars at early ages [38]. It can also be speculated that the hydration process had been completed after $28 \mathrm{~d}$, which could effectively relieve the drying shrinkage of CEA mortars from $28 \mathrm{~d}$ to $56 \mathrm{~d}$.

Furthermore, the drying shrinkage of CEA mortars decreased with increasing proportions of EE replacing EA. The drying shrinkage of CEA mortar-IV was lowest among the four types of CEA mortars, regardless of the curing age. This indicates that EE, as a partial replacement of EA, played a role in reducing the drying shrinkage of CEA mortars. This may be because EE, with the preferable bond strength, wrapped around the surface of hydration products, resulting in a stronger interlaced network structure in CEA mortar. This plays the role of a microfiber, thus restricting particle movement in CEA mortars [38].

3.5. Erosion Resistance. Figure 11(a) presents the mass loss and mechanical strength loss of CEA mortars immersed in the acid solution for $60 \mathrm{~d}$. The acid in solution reacts with $\mathrm{Ca}(\mathrm{OH})_{2}$ in cement mortar, resulting in a decrease of mass and mechanical strength of the CEA mortars [39]. Therefore, a smaller value of mass loss and mechanical strength loss indicates better erosion resistance of CEA mortars. The mass loss and mechanical strength loss (flexural strength loss and compressive strength loss) of CEA mortars decreased with increasing proportions of EE replacing EA. The mass loss of CEA mortar-I reached $0.3 \%$. Compared with CEA mortar-I, the mass loss of CEA mortar-IV decreased by $33.3 \%$. In addition, the flexural strength loss and compressive strength loss of CEA mortar-I reached $10.5 \%$ and $10.1 \%$, respectively. Compared with CEA mortar-I, the flexural strength loss and compressive strength loss of CEA mortar-IV decreased to $8.2 \%$ and $7.4 \%$, respectively. This indicates that $\mathrm{EE}$ addition could further improve the erosion resistance of CEA mortars to the acid solution.

Sulfate in the sulfate solution reacts with calcium aluminate hydrate $(\mathrm{CAH})$ in cement mortars to form ettringite with a volume of about 2.5 times than that of $\mathrm{CAH} \mathrm{[40].} \mathrm{The}$ internal structure of CEA mortars is destroyed, and the mechanical strength decreases because of the expansion stress caused by ettringite. However, the ettringite attached to the surface of cement mortars will increase their mass. A negative mass loss, as shown in Figure 11(b), indicates an increasing mass of CEA mortars immersed in a sulfate solution. With increasing replacement content of EA by EE, the increase in the mass and the loss of mechanical strength decreased. This indicates that the partial replacement of EA by EE could also further improve the erosion resistance of CEA mortars to the sulfate solution. This is mainly because of the filling of voids in CEA mortars by epoxy resin and the integration of asphalt and hydration products. Moreover, 


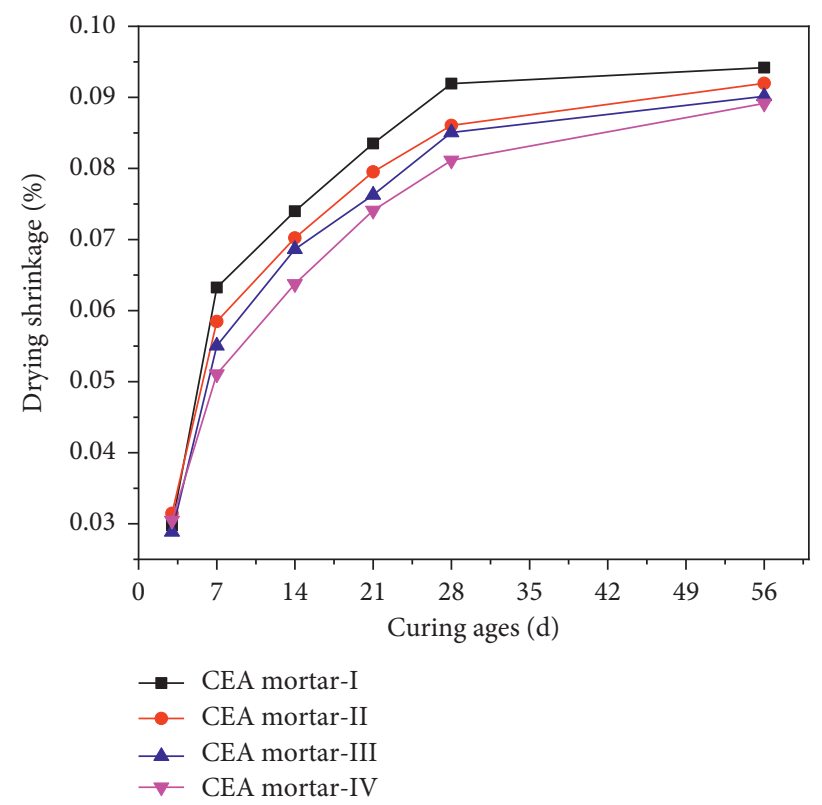

Figure 10: Drying shrinkage of cement emulsified asphalt mortars at different ages.

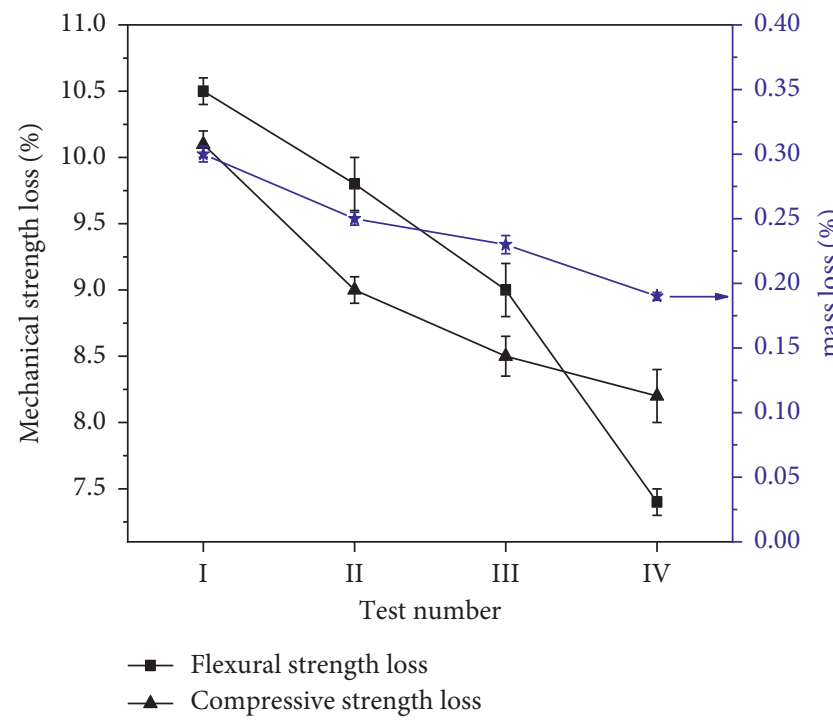

(a)

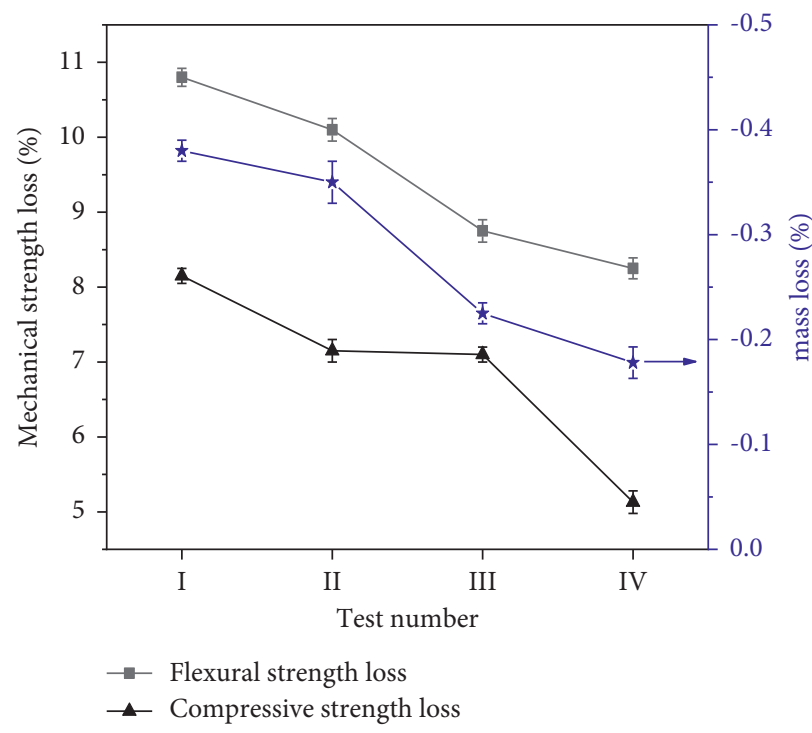

(b)

FIGURE 11: Mass loss and mechanical strength loss of cement emulsified asphalt mortars immersed in erosion solutions: (a) acid solution and (b) sulfate solution.

the denser network structure of CEA mortars containing EE improves the compactness of CEA mortars, thus impeding the infiltration of erosion medium into CEA mortars.

3.6. Microstructure Analysis. The microstructure of CEA mortar-I (without EE) and CEA mortar-IV (with EE) was characterized by SEM. As presented in Figure 12, asphalt and cement hydration products overlap (Figure 12(a)), forming a stable cement-asphalt structure at the age of $28 \mathrm{~d}$ (Figure 12(b)). Moreover, in Figure 12(c), epoxy resin filled the voids in CEA mortars and integrated both asphalt and hydration products to form a strong and dense network structure. With the curing of epoxy resin, CEA mortar formed a stronger, continuously cross-linked network structure at the age of $28 \mathrm{~d}$ (Figure 12(d)). It can be inferred that EE plays an important role in improving the performance of CEA mortars with the partial replacement of EA by EE. The stronger network structure formed in the CEA mortars containing EE can improve the compactness, thus improving the mechanical properties and durability of CEA mortars. 


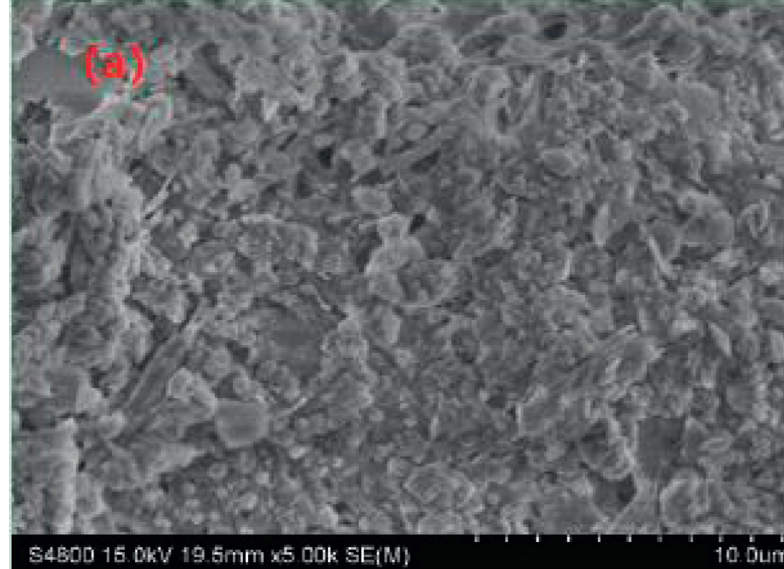

(a)

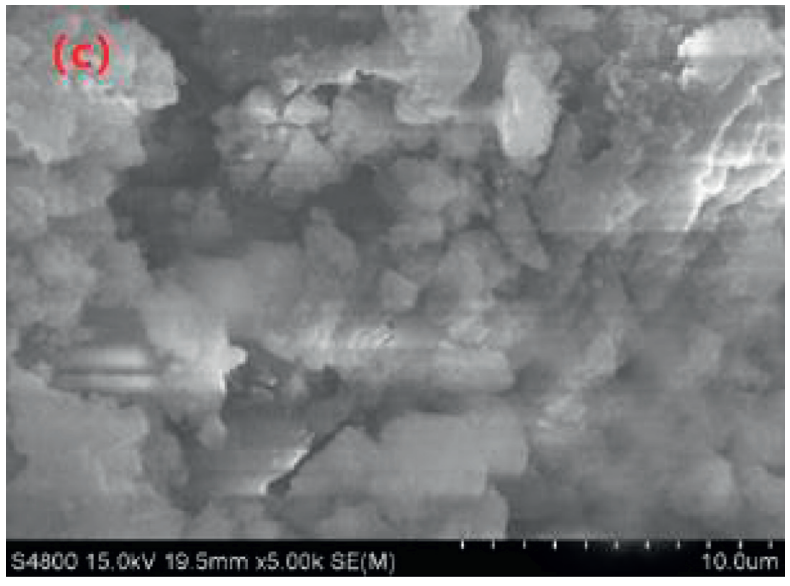

(c)

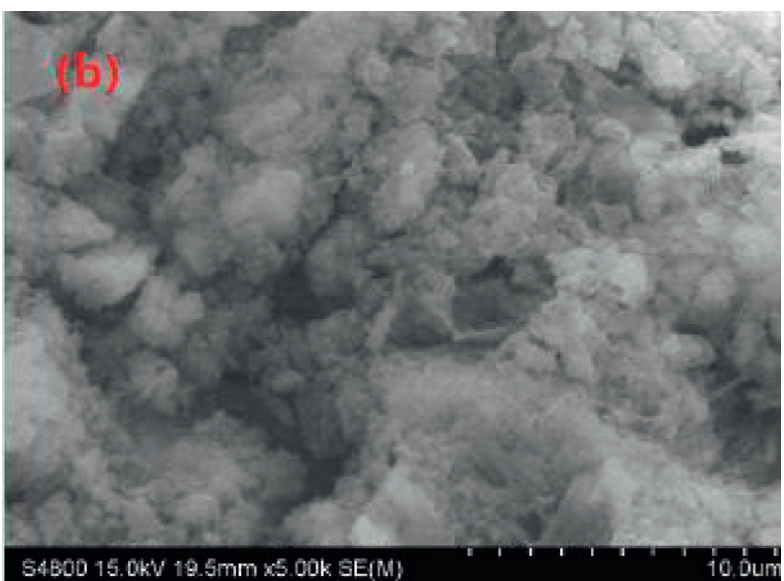

(b)

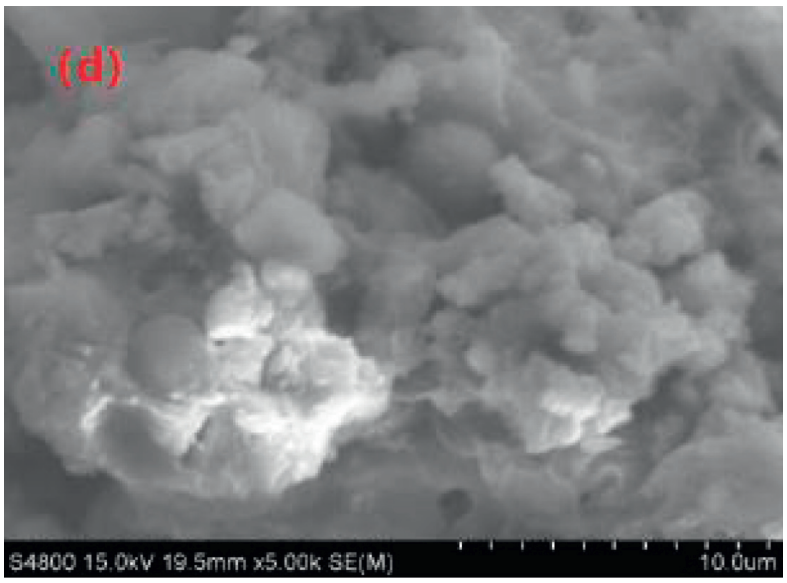

(d)

FIGURE 12: Scanning electron microscopic images of cement emulsified asphalt mortars: (a) cement emulsified asphalt mortar-I (3 d), (b) cement emulsified asphalt mortar-I (28 d), cement emulsified asphalt mortar-IV (3 d), and cement emulsified asphalt mortar-IV (28 d).

\subsection{Properties of Cement Emulsified Asphalt Mortars versus} Standard values. As mentioned in Section 1, CEA mortars can be used as repairing materials for cement pavement or cement infrastructures. Thus, CEA mortars must meet the minimum requirements for repairing materials. Table 6 presents the basic requirements for CEA mortars according to Chinese standard JC/T 2381-2016 The Repairing Mortar, and the obtained test results. The properties of all types of CEA mortars in the test, including flexural bond strength, mechanical strength, toughness, RCF, and drying shrinkage, met the requirements of the standard values. The exception is the flexural strength of CEA mortar-I, which only reached $5.4 \mathrm{MPa}$ at $28 \mathrm{~d}$, remaining below the minimum requirement of $6.0 \mathrm{MPa}$. This is mainly because of EA, which lowers the mechanical strength of CEA mortars because of its low modulus [34, 35].

In addition, a comparison of the test results of CEA mortars-I, II, III, and IV with standard values shows that the partial replacement of EA by EE played a role in enhancing the properties of CEA mortars. Equations (7) and (8) were applied to quantify the improvement degree on the properties of CEA mortars compared with standard values. The results are presented in Figure 13.

$$
\begin{gathered}
\text { Degree }_{i}=\frac{\left(V_{\text {Requirementsi }}-V_{\text {testi }}\right)}{V_{\text {Requirementsi }}} * 100 \%, \\
\text { Degree }_{j}=\frac{\left(V_{\text {test } j}-V_{\text {Requirements } j}\right)}{V_{\text {Requirements } j}} * 100 \%,
\end{gathered}
$$

where Degree ${ }_{i}$ refers to the improvement degree of CEA mortars for flexural bond strength, flexural strength, and compressive strength (\%); Degree ${ }_{j}$ refers to the degree of improvement of CEA mortars for RCF and drying shrinkage (\%); $V_{\text {requirementsi }}$ and $V_{\text {requirementsj }}$ refer to the standard values; and $V_{\text {test } i}$ and $V_{\text {test }}$ refer to the test values of CEA mortars.

Figure 13 shows that the improvement degree on the properties of CEA mortars increased with increasing the proportion of EE replacing EA. Moreover, the partial replacement of EA by EE exerted the most significant improvement effect on the bond strength of CEA mortars. The bond strength of CEA mortar-IV was enhanced by $115 \%$ compared with the standard value. However, the partial replacement of EA by EE had almost no enhancement effect on the toughness of CEA mortars. In summary, when EA was partially replaced by EE, the improvement degree on 
TABLE 6: Basic requirements for repairing mortar.

\begin{tabular}{|c|c|c|c|c|c|c|}
\hline \multirow{2}{*}{ Item } & \multicolumn{4}{|c|}{ Test values of CEA mortars } & \multirow{2}{*}{ Requirements } & \multirow{2}{*}{ Test method in standard } \\
\hline & $\mathrm{I}$ & II & III & IV & & \\
\hline Flexural bond strength $(28 \mathrm{~d})(\mathrm{MPa})$ & 3.2 & 3.5 & 3.9 & 4.3 & $\geq 2.0 \mathrm{MPA}$ & JC/T2381-2016 (China) \\
\hline Flexural strength $(28 \mathrm{~d})(\mathrm{MPa})$ & 5.4 & 6.3 & 6.6 & 7.1 & $\geq 6.0 \mathrm{MPa}$ & $\begin{array}{c}\text { GB/T 17671-1999 (China) } \\
\text { DL/T5126-2001 (China) }\end{array}$ \\
\hline Compressive strength $(28 \mathrm{~d})(\mathrm{MPa})$ & 35.4 & 40.8 & $42 . .3$ & 44.3 & $\geq 30 \mathrm{MPa}$ & $\begin{array}{c}\text { GB/T 17671-1999 (China) } \\
\text { DL/T5126-2001 (China) }\end{array}$ \\
\hline $\mathrm{RCF}(28 \mathrm{~d})(\mathrm{MPa})$ & 6.56 & 6.48 & 6.40 & 6.21 & $\leq 7.0 \mathrm{MPA}$ & $\begin{array}{l}\text { GB/T 17671-1999 (China) } \\
\text { DL/T5126-2001 (China) }\end{array}$ \\
\hline Impact toughness $(28 \mathrm{~d})(\mathrm{N} \cdot \mathrm{m})$ & 172.6 & 176.0 & 183.4 & 187.0 & - & - \\
\hline Drying shrinkage (28d) (\%) & 0.091 & 0.086 & 0.085 & 0.081 & $\leq 0.10 \%$ & JC-T603-2004 (China) \\
\hline Erosion resistance & - & - & - & & - & - \\
\hline
\end{tabular}

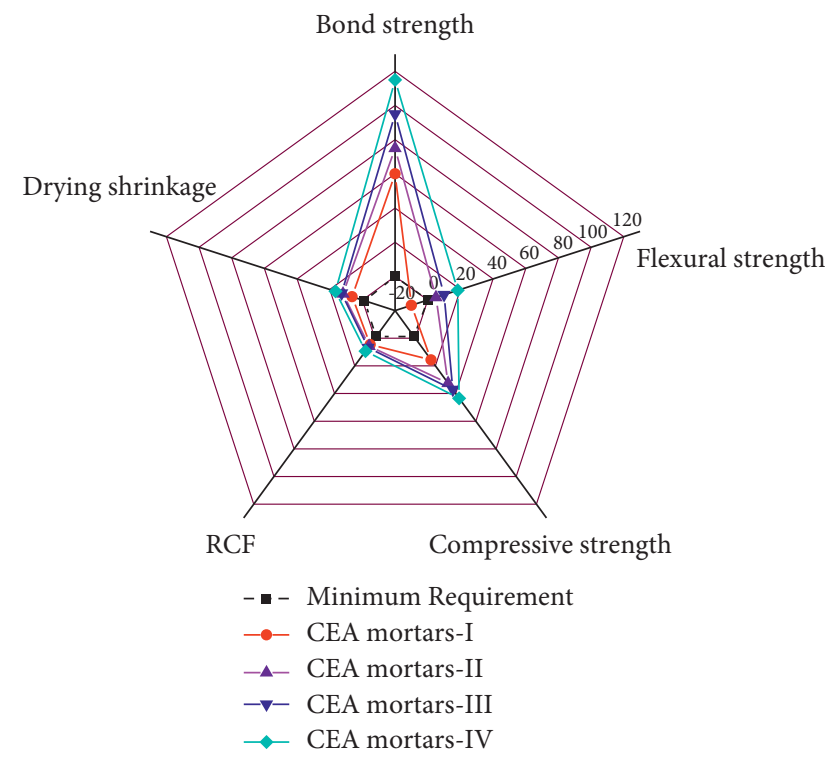

FIGURE 13: Improvement degree on the properties of cement emulsified asphalt mortars compared with standard values.

the properties of CEA mortars ranked as follows: bond strength $>$ compressive strength $>$ compressive strength $>$ drying shrinkage $>$ toughness.

\section{Conclusions}

In this study, EA in CEA mortar was partly replaced by EE with additions varying from $0 \%$ to $30 \%$ (at increments of 10\%). The properties of resulting CEA mortars (I, II, III, and IV) were investigated. The following conclusions could be drawn:

(1) EE as partial replacement of EA improves the mechanical strength and bond strength of CEA mortars. The mechanical strength and bond strength of CEA mortar-IV increased maximally among all four types of CEA mortars at ages of 3,7 , and $28 \mathrm{~d}$. A good correlation was found between the proportions of $\mathrm{EE}$ replacing the $\mathrm{EE}$ and the bond strength of CEA mortar.

(2) The partial replacement of EA by EE had no apparent improvement effect on the toughness of CEA mortars. Compared with CEA mortar-I, the RCF of the CEA mortar-IV merely decreased by $5.3 \%$, and the impact energy absorbed by CEA mortar-IV merely increased by $8.3 \%$. Moreover, the impact energy absorbed by specimens after initial cracking decreased with increasing proportions of $\mathrm{EE}$ replacing EA.

(3) The EE as a partial replacement of EA played a role in improving the drying shrinkage and the erosion resistance of CEA mortars. The drying shrinkage of CEA mortar-IV was lowest among the four types of CEA mortars. The mass loss and mechanical strength loss of CEA mortar-IV immersed in erosion solution were also lowest among the four types of CEA mortars.

(4) EE and EA mix well and form a network interpenetrating structure at proportions of EE replacing EA below 30\%. The stronger network structure formed in the CEA mortars containing EE improved the compactness and bonding performance between the components of CEA mortars, thus improving the performance of CEA mortars.

Based on the above properties, the partial replacement of EA by EE is suggested to enhance the properties of CEA mortars.

\section{Future Work}

In the future work, the hardening mechanism and microstructure of CEA mortars containing EE will be studied. Moreover, the reaction principle of EE in CEA mortars will be further assessed.

\section{Data Availability}

The data used to support the findings of this study are available from the corresponding author upon request.

\section{Conflicts of Interest}

The authors declare that there no conflicts of interest regarding the publication of this article.

\section{Acknowledgments}

This work was supported by the Western Transportation Construction Science and Technique Program (2013318J09230) and the Natural Science Foundation of Qinghai Province (no. 2020-ZJ-736). 


\section{References}

[1] J. J. Assaad, "Development and use of polymer-modified cement for adhesive and repair applications," Construction and Building Materials, vol. 163, pp. 139-148, 2018.

[2] J. Shi, B. Liu, J. Qin, J. Jiang, X. Wu, and J. Tan, "Experimental study of performance of repair mortar: evaluation of in-situ tests and correlation analysis," Journal of Building Engineering, vol. 31, 2020.

[3] B. Liu, J. Shi, M. Sun, Z. He, H. Xu, and J. Tan, "Mechanical and permeability properties of polymer-modified concrete using hydrophobic agent," Journal of Building Engineering, vol. 31, 2020.

[4] Y. Li, X. Li, and Y. Tan, "Effect of aging on fatigue performance of cement emulsified asphalt repair material," Construction and Building Materials, vol. 292, Article ID 123417, 2021.

[5] C. Yang, J. Li, Z. Zhu, S. Wang, and Y. Liu, "Characterization of sulphoaluminate cement-asphalt emulsion mortar for cement and asphalt mortar repair," Frontiers in Materials, vol. 7, Article ID 101, 2020.

[6] Y. Liu, F. Wang, M. Liu, and S. Hu, "A microstructural approach to adherence mechanism of cement and asphalt mortar (CA mortar) to repair materials," Construction and Building Materials, vol. 66, pp. 125-131, 2014.

[7] H. Peng, Y. Zhang, J. Wang, Y. Liu, and L. Gao, "Interfacial bonding strength between cement asphalt mortar and concrete in slab track," Journal of Materials in Civil Engineering, vol. 31, no. 7, 2019.

[8] J. Liu, X. Wen, Z. Zhang, S. Li, and Z. Zeng, "Influence of the stabilizer on interfacial bonding behavior of cement asphalt mortar in slab ballastless track," Journal of Materials in Civil Engineering, vol. 30, no. 10, Article ID 04018245, 2018.

[9] Y. Zhang, X. Cai, L. Gao, and K. Wu, "Improvement on the mechanical properties of CA mortar and concrete composite specimens in high-speed railway by modification of interlayer bonding," Construction and Building Materials, vol. 228, Article ID 116758, 2019.

[10] C. Akay, M. Ç. Tanış, E. Mumcu, M. A. Kılıçarslan, and M. Şen, "Influence of nano alumina coating on the flexural bond strength between zirconia and resin cement," The journal of advanced prosthodontics, vol. 10, no. 1, p. 43, 2018.

[11] S. Papaioannou, R. Argyropoulou, C. Kalogiannidou et al., "Mechanical and adhesion properties of polymer-modified cement mortars in relation with their microstructure," The Journal of Adhesion, vol. 95, no. 2, pp. 126-145, 2019.

[12] Y.-K. Jo, "Adhesion in tension of polymer cement mortar by curing conditions using polymer dispersions as cement modifier," Construction and Building Materials, vol. 242, Article ID 118134, 2020.

[13] L. Xiao, Y. Jin, and L. Gu, "Preparation and properties of a new composite of epoxy emulsion (EEM) modified cement," Journal of Wuhan University of Technology-Materials Science Edition, vol. 24, no. 5, p. 843, 2009.

[14] Q. Xiang and F. Xiao, "Applications of epoxy materials in pavement engineering," Construction and Building Materials, vol. 235, 2020.

[15] Z. Zheng, Y. Li, S. a. He, X. Ma, X. Zhu, and S. Li, "High density and high strength cement-based mortar by modification with epoxy resin emulsion," Construction and Building Materials, vol. 197, pp. 319-330, 2019.

[16] B. Pang, Y. Zhang, and G. Liu, "Study on the effect of waterborne epoxy resins on the performance and microstructure of cement paste," Construction and Building Materials, vol. 167, pp. 831-845, 2018.

[17] J. Zuo, H. Li, B. Dong, C. Luo, and D. Chen, "Mechanical properties and resistance to chloride ion permeability of epoxy emulsion cement mortar reinforced by glass flake," Construction and Building Materials, vol. 155, pp. 137-144, 2017.

[18] Y. Gu, B. Tang, L. He, F. Yang, H. Wang, and J. Ling, "Compatibility of cured phase-inversion waterborne epoxy resin emulsified asphalt," Construction and Building Materials, vol. 229, Article ID 116942, 2019.

[19] M. Liu, S. Han, J. Pan, and W. Ren, "Study on cohesion performance of waterborne epoxy resin emulsified asphalt as interlayer materials," Construction and Building Materials, vol. 177, pp. 72-82, 2018.

[20] R. Li, Z. Leng, Y. Zhang, and X. Ma, "Preparation and characterization of waterborne epoxy modified bitumen emulsion as a potential high-performance cold binder," Journal of Cleaner Production, vol. 235, pp. 1265-1275, 2019.

[21] Z. Wang, X. Shu, T. Rutherford, B. Huang, and D. Clarke, "Effects of asphalt emulsion on properties of fresh cement emulsified asphalt mortar," Construction and Building Materials, vol. 75, pp. 25-30, 2015.

[22] Y. Du, L. Kong, and T. Wei, "Laboratory investigation into early-age strength improvement of cold recycled asphalt mixture containing asphalt emulsion and cement," Advances in Civil Engineering, vol. 2019, Article ID 7274204, 10 pages, 2019.

[23] Q. Xia, J. Wen, X. Tang et al., "Optimal preparation and degradation characterization of repair mortar containing waterborne epoxy resin emulsions," Construction and Building Materials, vol. 298, Article ID 123839, 2021.

[24] Y. Tan, J. Ouyang, J. Lv, and Y. Li, "Effect of emulsifier on cement hydration in cement asphalt mortar," Construction and Building Materials, vol. 47, pp. 159-164, 2013.

[25] J. Ouyang, L. Hu, W. Yang, and B. Han, "Strength improvement additives for cement bitumen emulsion mixture," Construction and Building Materials, vol. 198, pp. 456-464, 2019.

[26] A. Buoso, L. Coppola, and F. Corazza, "Electrical properties of carbon nanotubes cement composites for monitoring stress conditions in concrete structures," Applied Mechanics and Materials, Transactions Tech Publications, Stafa-Zurich. Switzerland, 2011.

[27] M. L. Vo and J. Plank, "Evaluation of natural rubber latex as film forming additive in cementitious mortar," Construction and Building Materials, vol. 169, pp. 93-99, 2018.

[28] S.-j. Liu, Q.-q. Hu, F.-q. Zhao, and X.-m. Chu, "Utilization of steel slag, iron tailings and fly ash as aggregates to prepare a polymer-modified waterproof mortar with a core-shell styrene-acrylic copolymer as the modifier," Construction and Building Materials, vol. 72, pp. 15-22, 2014.

[29] F. Qiao, C. K. Chau, and Z. Li, "Property evaluation of magnesium phosphate cement mortar as patch repair material," Construction and Building Materials, vol. 24, no. 5, pp. 695-700, 2010.

[30] J. Luo, Q. Li, T. Zhao, S. Gao, and S. Sun, "Bonding and toughness properties of PVA fibre reinforced aqueous epoxy resin cement repair mortar," Construction and Building Materials, vol. 49, pp. 766-771, 2013.

[31] S. R. Abid, M. L. A. Hussein, S. H. Ali, and A. a. F. Kazem, "Suggested modified testing techniques to the ACI 544-R repeated drop-weight impact test," Construction and Building Materials, vol. 244, 2020. 
[32] L. Tri Ho Minh, D.-W. Park, J.-W. Seo, and P. Tam Minh, "Anti-chemical resistance and mock-up test performance of cement asphalt mortar modified with polymer for ballast stabilizing," Construction and Building Materials, vol. 232, 2020.

[33] M. Wang, R. Wang, H. Yao et al., "Research on the mechanism of polymer latex modified cement," Construction and Building Materials, vol. 111, pp. 710-718, 2016.

[34] P. Nanthavisit, P. Jitsangiam, and P. Pichayapan, "Effect of cement-asphalt emulsion mortar based on a laboratory investigation," Key Engineering Materials, vol. 801, pp. 404-409, 2019.

[35] H. Song, J. Do, and Y. Soh, "Feasibility study of asphaltmodified mortars using asphalt emulsion," Construction and Building Materials, vol. 20, no. 5, pp. 332-337, 2006.

[36] Z. Leiben, X. Wang, Z. Wang, B. Yang, Y. Tian, and R. He, "Damping characteristics of cement asphalt emulsion mortars," Construction and Building Materials, vol. 173, pp. 201-208, 2018.

[37] B. Liu and D. Liang, "Effect of mass ratio of asphalt to cement on the properties of cement modified asphalt emulsion mortar," Construction and Building Materials, vol. 134, pp. 39-43, 2017.

[38] T. Rutherford, Z. Wang, X. Shu, B. Huang, and D. Clarke, "Laboratory investigation into mechanical properties of cement emulsified asphalt mortar," Construction and Building Materials, vol. 65, pp. 76-83, 2014.

[39] P. Sereda, Slag on the Durability of Cement Mortar by Carbonic Acid Attack-, Durability of Building Materials and Components: Proceedings of the First International Conference, p. 364, ASTM International, West Conshohocken, PA, USA, 1980.

[40] M. M Collepardi, "A state-of-the-art review on delayed ettringite attack on concrete," Cement and Concrete Composites, vol. 25, no. 4-5, pp. 401-407, 2003. 